\title{
Contribution of respiratory acidosis to diaphragmatic fatigue at exercise
}

\author{
S. Jonville*, N. Delpech*, A. Denjean*,\#
}

Contribution of respiratory acidosis to diaphragmatic fatigue at exercise. S. Jonville, N. Delpech, A. Denjean. C ERS Journals Ltd 2002.

ABSTRACT: The factors that may modulate ventilatory muscle fatigue during exercise are controversial. In this study the contribution of acidosis to exercise-induced diaphragmatic fatigue was investigated, using measurements of the twitch mouth pressure response $\left(\mathrm{tw}, \boldsymbol{P}_{\mathrm{mo}}\right)$ to cervical magnetic stimulation.

After learning sessions, 14 healthy subjects performed two cycling tests (at $60 \%$ of maximal aerobic power for $16 \mathrm{~min}$ ), one while breathing spontaneously (mean minute ventilation $\left.\left(V^{\prime} \mathrm{E}\right) 67.9 \mathrm{~L} \cdot \mathrm{min}^{-1}\right)$ and the other while hypoventilating voluntarily $\left(\right.$ mean $\left.V^{\prime} \mathrm{E} 53.8 \mathrm{~L} \cdot \mathrm{min}^{-1}\right)$. Exercise was voluntarily set at a moderate power to avoid a fatiguing effect of exercise per se.

As compared with spontaneous breathing (SB), voluntary hypoventilation (VHV) significantly increased mean carbon dioxide tension in arterial blood $\left(\mathrm{Pa}_{\mathrm{a}}, \mathrm{CO}_{2}\right)$ $(51 \mathrm{mmHg}$ versus $41 \mathrm{mmHg})$ and significantly decreased arterial $\mathrm{pH}(7.28$ versus 7.34). After $10 \mathrm{~min}$ of $\mathrm{SB}$ test, tw, $\boldsymbol{P}_{\mathrm{mo}}$ was unchanged compared to the baseline value (19.1 versus $18.5 \mathrm{cmH}_{2} \mathrm{O}$ ) whereas tw, $P$ mo fell significantly as compared to baseline $\left(17.1\right.$ versus $\left.18.5 \mathrm{cmH}_{2} \mathrm{O}\right)$ and to $\mathrm{SB}\left(17.1\right.$ versus $\left.19.1 \mathrm{cmH}_{2} \mathrm{O}\right)$ after the VHV test.

The results of this study suggest that exposure to hypercapnia may impair respiratory muscle function. This impairment could be more clinically relevant in patients with chronic obstructive lung disease.

Eur Respir J 2002; 19: 1079-1086.
*Human Performance Laboratory, Sports Sciences Dept, University of Poitiers, and "Exercise Respiratory Physiology, University Hospital of Poitiers, France.

Correspondence: S. Jonville, Laboratoire d'analyse de la performance motrice humaine, Faculté des Sciences du Sport, 4 allée Jean Monnet, 86000 Poitiers, France.

Fax: 33549453396

E-mail: sophie.jonville@etu. univ-poitiers.fr

Keywords: Cervical magnetic stimulation

hypercapnia mouth pressure respiratory muscles

Received: August 12001 Accepted after revision January 16 2002
Studies showing that the diaphragm is susceptible to fatigue [1-3] have led to a flurry of research into the factors that influence diaphragmatic function. COAST et al. [4] recently demonstrated that increased work of breathing is not sufficient to explain the respiratory muscle fatigue seen during exercise. Several factors linked to exercise have been suggested as causes of inspiratory muscle fatigue, including: 1) competition for blood flow between the motor skeletal muscles and the diaphragm; and 2) accumulation in the diaphragm and other inspiratory muscles of metabolites produced by motor skeletal muscles [5]. Acidosis is among the major extracellular modifications seen during exercise, and can be considered as a factor that contributes to muscular fatigue [6]. Whether hypercapnia impairs respiratory muscle function is a matter of debate. In vivo [7] and in vitro [8,9] animal studies suggest that hypercapnia-induced acidosis may affect diaphragmatic contractility, whereas others do not [10]. Human studies are also controversial. JUAN et al. [11] found that hypercapnia was associated with accelerated diaphragmatic fatigue while MADOR et al. [12] refute this. Using hyperventilation, RAFFERTY et al. [13] showed that hypercapnia may reduce diaphragm contractility immediately after maximal voluntary ventilation but it did not intensify long-lasting fatigue in these conditions.

To the best of the authors' knowledge, the possible contribution of acidosis to diaphragmatic fatigue during exercise has never been evaluated in humans using cervical magnetic stimulation (CMS) of the phrenic nerves [14]. This method allows reliable and noninvasive measurement of respiratory muscle strength during nonvolitional contraction.

To determine whether respiratory acidosis may contribute to diaphragmatic fatigue during exercise, normal subjects were submitted to two exercise sessions, with an intensity of $60 \%$ of maximal aerobic power. One trial was performed during normocapnia produced by spontaneous breathing (SB), while in the other trial hypercapnia was produced by voluntary hypoventilation (VHV). Diaphragmatic fatigue was assessed using measurement of the twitch mouth pressure response $(\mathrm{tw}, P \mathrm{mo})$ to $\mathrm{CMS}$ of the phrenic nerves. In an additional study, tw, $P$ mo was used concomitantly with twitch transdiaphragmatic pressure $(\mathrm{tw}, P \mathrm{di})$ to insure the adequacy of $\mathrm{tw}, P \mathrm{mo}$ in the detection of diaphragmatic fatigue.

\section{Methods}

\section{Subjects}

Fourteen healthy males aged $23.9 \pm 1.7$ yrs gave their informed consent for the study, which was approved 
Table 1. - Main characteristics of the study subjects

\begin{tabular}{|c|c|c|c|c|c|c|}
\hline Subject no. & Age yr & Height $\mathrm{cm}$ & Weight kg & $V^{\prime} \mathrm{O}_{2} \max \mathrm{L} \cdot \min ^{-1}$ & MAP W & Load W \\
\hline 1 & 24 & 187 & 90 & 4.0 & 375 & 210 \\
\hline 2 & 22 & 175 & 72 & 4.3 & 375 & 220 \\
\hline 3 & 26 & 183 & 79 & 3.5 & 300 & 180 \\
\hline 4 & 24 & 168 & 68 & 3.4 & 300 & 180 \\
\hline 5 & 25 & 179 & 73 & 3.7 & 325 & 190 \\
\hline 6 & 21 & 176 & 75 & 4.5 & 350 & 210 \\
\hline 7 & 22 & 186 & 70 & 3.7 & 300 & 180 \\
\hline 8 & 24 & 176 & 70 & 3.9 & 425 & 290 \\
\hline 9 & 24 & 186 & 70 & 3.6 & 325 & 190 \\
\hline 10 & 26 & 191 & 79 & 4.0 & 375 & 220 \\
\hline 11 & 22 & 171 & 65 & 3.5 & 325 & 200 \\
\hline 12 & 25 & 180 & 77 & 4.1 & 325 & 185 \\
\hline 13 & 26 & 178 & 81 & 2.9 & 300 & 170 \\
\hline 14 & 23 & 178 & 74 & 2.9 & 300 & 170 \\
\hline Mean \pm SD & $23.9 \pm 1.7$ & $179.6 \pm 6.4$ & $74.5 \pm 6.4$ & $3.7 \pm 0.5$ & $336 \pm 39$ & $200 \pm 31$ \\
\hline
\end{tabular}

$V^{\prime} \mathrm{O}_{2} \max$ : maximal oxygen intake; MAP: maximal aerobic power; Load: work load.

by the appropriate ethics committee. All 14 subjects denied a personal or familial history of epilepsy. None wore a pacemaker or an implanted electronic device that would have contraindicated CMS. Baseline characteristics of the study subjects are reported in table 1.

\section{Preliminary exercise testing and voluntary hypoventilation}

At the first visit, each subject underwent a physical examination and a 12-lead electrocardiogram (ECG), and then performed an incremental exercise test to allow maximal oxygen uptake $\left(V^{\prime} \mathrm{O}_{2} \max \right)$ determination as follows: the subjects exercised to exhaustion on an electronically-braked cycle ergometer (Bosch Erg 602; Dimeq, Berlin, Germany). After a 10-min warmup at $75 \mathrm{~W}$, the load was increased $\left(25 \mathrm{~W} \cdot \mathrm{min}^{-1}\right)$ until the subject was unable to continue despite encouragement. The subject breathed through a facemask (Hans Rudolph, Kansas City, MO, USA), and expired gases were analysed breath-by-breath using an automated system (CPX, Medical Graphics, St Paul, MN, USA). Expired gas flow was measured using a pneumotachograph (Type 3; Hans Rudolph). Oxygen uptake $\left(V^{\prime} \mathrm{O}_{2}\right)$, and carbon dioxide production $\left(V^{\prime} \mathrm{CO}_{2}\right)$ were averaged over the last $15 \mathrm{~s}$ of each min. End-tidal pressures of oxygen $\left(P \mathrm{ET}, \mathrm{O}_{2}\right)$ and carbon dioxide $\left(P\right.$ ET, $\left.\mathrm{CO}_{2}\right)$, expiratory flow $\left(V^{\prime} \mathrm{E}\right)$, tidal volume $(V \mathrm{~T})$, respiratory rate $(\mathrm{RR})$, and inspiratory oxygen fraction $\left(F \mathrm{I}, \mathrm{O}_{2}\right)$ were monitored continuously. Criteria for $V^{\prime} \mathrm{O}_{2} \max$ determination were: 1) stabilization of $V^{\prime} \mathrm{O}_{2}$ despite a further increase in workload, 2) attainment of the age-predicted maximal cardiac frequency (220-age), and 3$)$ a respiratory exchange ratio $>1.15$. Cardiac frequency was recorded continuously by four ECG leads.

During the next 3 weeks (once or twice a week), the subjects participated in learning sessions, during which they were instructed to voluntarily decrease their $V^{\prime} \mathrm{E}$ while exercising at $60 \%$ of their predetermined maximal aerobic power (MAP) for $10 \mathrm{~min}$. VHV was considered learned when the subject was able to voluntarily decrease $V^{\prime} \mathrm{E}$, mainly by decreasing
$V \mathrm{~T}$, for at least $10 \mathrm{~min}$. The subjects breathed through a face mask connected to a three-way valve. A pneumotachograph was connected to the inspiratory port of the circuit for breath-by-breath automated gas analysis (as described earlier). Inspired airflow was adjusted using a flow meter. Inspired air was humidified after entry into a $10-\mathrm{L}$ balloon placed on the inspiratory breathing circuit. The subjects used the balloon as a target to control their $V \mathrm{~T}$.

\section{Voluntary hypoventilation, spontaneous breathing}

During experimental sessions, the subjects performed two standardized tests. Because it was important that exercise by itself did not induce fatigue, its intensity was chosen voluntarily moderate $(60 \%$ of the MAP). This intensity was similar during VHV and during SB.

After a 12-min warm-up, power was increased to $60 \% \mathrm{MAP} \pm 10 \mathrm{~W}$ (fig. 1). After $3 \mathrm{~min}$, the subjects

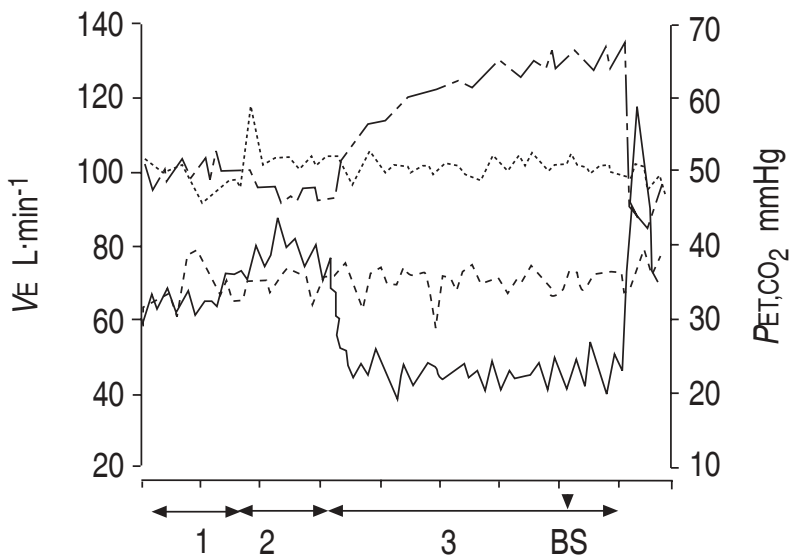

Fig. 1.- Ventilatory output $\left(V^{\prime} \mathrm{E}\right)$ and end-tidal pressure of oxygen $\left(P\right.$ ET, $\left.\mathrm{CO}_{2}\right)$ during voluntary hypoventilation (VHV) and spontaneous breathing (SB) tests in one subject. 1: last 3 min of warmup; 2: familiarization with the breathing circuit; 3: 10 min exercise with either VHV or SB; BS: blood sampling. - - -: VE during SB; -: VE during VHV; $\cdots \cdots \cdots \cdot P_{\mathrm{ET}, \mathrm{CO}_{2}}$ during $\mathrm{SB} ;-\cdots-: \mathrm{PET}_{\mathrm{C}} \mathrm{CO}_{2}$ during VHV. 
were connected to the breathing circuit for $13 \mathrm{~min}$. For the SB test, they were given no instructions about breathing, whereas for the VHV test they were asked to hypoventilate after breathing spontaneously through the system for $3 \mathrm{~min}$. Blood samples were drawn during the last minute of the SB and VHV periods. Each test was followed by a 2-min active postexercise period.

The following were required for study inclusion: 1) $>15 \%$ difference in $V^{\prime} \mathrm{E}$ between VHV and SB; 2) $>10 \%$ difference in $V \mathrm{~T}$ between VHV and $\mathrm{SB}$; 3) similar pedalling frequency and $R R$ values during VHV and SB; 4) >4-point difference in $\mathrm{pH}$ between VHV and SB; 5) normoxia during VHV as well as during $\mathrm{SB}$. $F \mathrm{I}, \mathrm{O}_{2}$ was maintained close to $23 \%$ during VHV and at $21.5 \%$ during $\mathrm{SB}$, in order to avoid hypoxia and possible hypoxia-induced metabolic acidosis.

To determine blood gases a radial artery blood sample was obtained from nine subjects during the last minute of exercise, under local anaesthesia (Emla 5\%; Astra, France). In the five other subjects, arterialized blood was taken from the earlobe previously warmed by application of ointment (Finalgon; Boehringer, Germany).

\section{Measurement of the twitch mouth pressure response}

Cervical magnetic stimulation. Five acceptable stimulations were used for each set of pressure measurement. Mouth pressure was measured using a differential pressure transducer (Validyne $\pm 150 \mathrm{cmH}_{2} \mathrm{O}$; Northridge, UK). The signal was acquired at $20,000 \mathrm{~Hz}$ for $260 \mathrm{~ms}$ after stimulation (MP100 Manager V3.2.6; Biopac systems Inc., Santa Barbara, CA, USA).

The subjects were seated comfortably in a quiet room and were asked to relax and to breathe freely. Throughout the stimulation session, they wore a nose clip and were connected to a mouthpiece with a small leak to prevent glottis closure. Airflow was measured using a pneumotachograph (Labmanager V4.34a; Masterscreen IOS; E. Jaeger $\mathrm{GmbH}$, Höchberg, Germany). Lung volumes were continuously monitored and plotted on a screen. An automatic nonresistant flow interrupter (type 6519; Bürkert, Germany) was placed between the pneumotachograph and the mouthpiece. This occlusion device (response time $50 \mathrm{~ms}$ ) was activated manually. The stimulation was triggered by the occlusion device at the functional residual capacity (FRC) by means of electronic synchronization. CMS was achieved using a Magstim 200 stimulator with a circular $90-\mathrm{mm}$ coil (maximum output 2 Teslas, pulse duration $0.05 \mathrm{~ms}$; Magstim, Whiteland, Dyfed, UK). The optimal position between fifth and seventh cervical vertebra for the coil was determined based on the pressure response at $60 \%$ of the maximum power output [14]. Stimulation was considered supramaximal when the tw, $P$ mo response reached a plateau and the electromyogram amplitude failed to increase further as the stimulation power increased [15]. Otherwise, power was set at $100 \%$.

\section{Electromyograms}

Surface recordings of the electromyograms (EMGs) of the right and left costal diaphragm were obtained using two pairs of disposable silver-cup electrodes. The electrodes were taped to the skin along the anterior axillary line in the seventh right and left intercostal spaces. Acquisition of the diaphragmatic EMG signals was performed as for tw, $P$ mo. The amplitude of the motor evoked potential (M-wave) was the parameter used in statistical analyses.

\section{Additional studies}

Study 1: in an additional set of experiments tw, $P$ mo and $t w, P$ di in response to CMS were recorded in four subjects before and $10 \mathrm{~min}$ after cycling at $85 \% V^{\prime} \mathrm{O}_{2} \max$ for $15 \mathrm{~min}$. The purpose of this study was to assess the amplitude of the fall in tw, $P$ mo following exercise, confirmed as fatiguing by $\mathrm{tw}, P$ di variations. Recordings of $\mathrm{tw}, P$ di were obtained by pressure transducers mounted on a gastrooesophageal catheter (CTO-2; Gaeltec Ltd, Scotland, UK).

Study 2: it was determined whether differences in ventilatory output could lead to different degrees of potentiation. The tw, $P$ mo obtained before, and 10 and $30 \mathrm{~min}$ after two exercises soliciting spontaneously ventilation to levels similar to $\mathrm{SB}$ and VHV were compared. Three subjects underwent both the exercise sessions following the same timing as the experimental sessions, i.e. warm up, habituation to the load, and $13 \mathrm{~min}$ of exercise while breathing into the circuit either at $60 \%$, or at $45 \%$ of MAP.

\section{Analysis}

The three median values of each set of five valid stimulations were used and averaged. Any aberrant values were excluded from the analysis. Measurements were considered invalid (and therefore were excluded) if any of the following occurred: 1) stimulation was not initiated at the FRC as determined based on the $V \mathrm{~T}$ plot or presence of an early decrease in mouth pressure or presence of a slight positive shift in mouth pressure before the decrease; 2) closure of the glottis was suspected based on abnormal pressure trace or a very low pressure value; 3) M-wave amplitude on the diaphragmatic EMG was not similar to the previous ones.

Data for tw, $P$ mo are reported as the means of the three median values \pm SD and $p$-values $<0.05$ were considered statistically significant.

The pressure, EMG amplitude, and ventilatory parameters changes over time and the effect of the exercise condition (VHV versus $\mathrm{SB}$ ) were assessed using two-way analysis of variance (ANOVA) for repeated measures. Post-hoc comparisons were made with the Newman-Keuls test. 


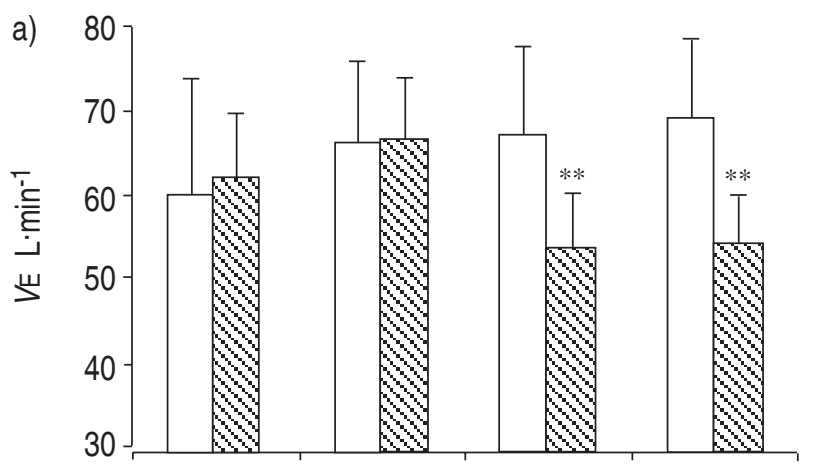

Table 2. - Individual values of carbon dioxide tension in arterial blood $\left(\mathrm{Pa}_{\mathrm{a}} \mathrm{CO}_{2}\right)$ and $\mathrm{pH}$ from arterial blood end-tidal pressure of oxygen sampled during the last $2 \mathrm{~min}$ of exercise with spontaneous breathing (SB) and voluntary hypoventilation (VHV)

\begin{tabular}{|c|c|c|c|c|}
\hline \multirow[t]{2}{*}{ Subject no. } & \multicolumn{2}{|c|}{$\mathrm{Pa}, \mathrm{CO}_{2} \mathrm{mmHg}$} & \multicolumn{2}{|c|}{$\mathrm{PH}$} \\
\hline & VHV & SB & VHV & SB \\
\hline $1^{\#}$ & 48 & & 7.28 & \\
\hline 2 & 56 & 42 & 7.25 & 7.35 \\
\hline $3^{\#}$ & & 40 & & 7.34 \\
\hline $4^{\#}$ & 53 & 37 & 7.26 & 7.32 \\
\hline $5^{\#}$ & 53 & 36 & 7.25 & 7.33 \\
\hline 6 & & 41 & 7.33 & 7.39 \\
\hline 7 & 52 & 44 & 7.32 & 7.36 \\
\hline 8 & 47 & 42 & 7.28 & 7.32 \\
\hline $9^{\#}$ & 50 & 42 & $\begin{array}{l}1.20 \\
7227\end{array}$ & 731 \\
\hline $10^{\#}$ & 53 & 45 & 7.29 & 7.35 \\
\hline $11^{\#}$ & 50 & 43 & 7.26 & 7.33 \\
\hline $12^{\#}$ & 52 & 39 & 7.26 & 7.40 \\
\hline Mean \pm SD & $51 \pm 3$ & $41 \pm 3$ & 7.28 & 7.34 \\
\hline
\end{tabular}
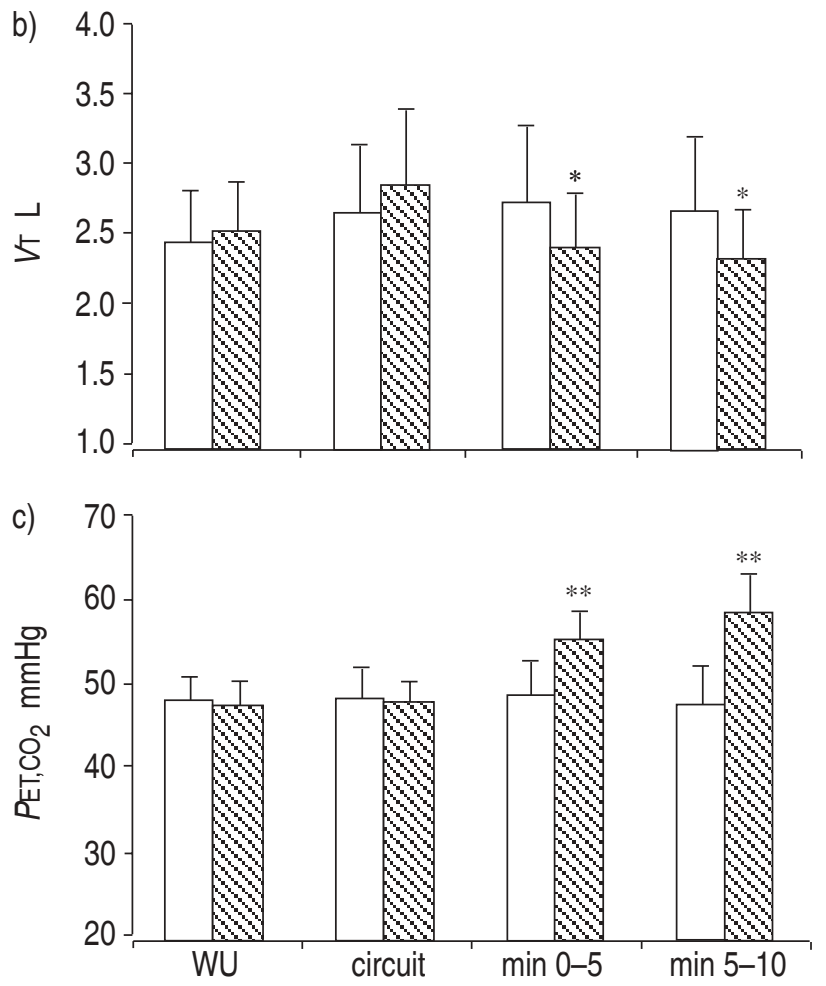

Fig. 2. -a) Ventilatory output $\left(V^{\prime} \mathrm{E}\right)$, b) tidal volume $\left(V_{\mathrm{T}}\right)$ and $\left.\mathrm{c}\right)$ end-tidal pressure of oxygen $\left(P \mathrm{ET}, \mathrm{CO}_{2}\right)$ during the last $3 \mathrm{~min}$ of warm-up (WU), 3 min of familiarization with the breathing circuit (circuit), min $0-5$ and 5-10 of spontaneous breathing (SB) ( $\square$ ) or voluntary hypoventilation (VHV) (\$) during the exercise tests. Data are presented as mean \pm SD. *: $\mathrm{p}<0.05$ between VHV and SB; $* *: \mathrm{p}<0.01$ difference between VHV and SB.

\section{Results}

Subjects exercised at $200 \pm 31$ W. During exercise, oxygen uptake was $75.7 \pm 6.5$ and $75.5 \pm 7.7 \% \quad V^{\prime} \mathrm{O}_{2} \max$ during VHV and SB, respectively.

\section{Breathing control and blood gases}

Two subjects were unable to hypoventilate by decreasing their $V \mathrm{~T}$. This left twelve subjects for analysis. During the VHV test in these twelve subjects, mean $V \mathrm{~T}$ was $2.3 \pm 0.3 \mathrm{~L}$ and mean $V^{\prime} \mathrm{E} 53.8 \pm$ $5.6 \mathrm{~L} \cdot \mathrm{min}^{-1}$, as compared to $2.7 \pm 0.5 \mathrm{~L}$ and $67.9 \pm$ $9.9 \mathrm{~L} \cdot \mathrm{min}^{-1}$ during the SB test (fig. 2).

\footnotetext{
\#: from arterialized blood.
}

Pronounced hypercapnia was seen following VHV as compared to $\mathrm{SB}\left(\mathrm{Pa}_{\mathrm{a}} \mathrm{CO}_{2} 51.3\right.$ and $41.3 \mathrm{mmHg}$, respectively; $P$ ET, $\mathrm{CO}_{2} 56.1$ and $47.7 \mathrm{mmHg}$, respectively) and was associated with a decrease in $\mathrm{pH}$ (7.28 during VHV and 7.34 during SB, table 2).

Diaphragmatic response to magnetic stimulation after exercise

Because the total EMG activity differed between the left and right hemidiaphragms, the signals for each were interpreted separately. For both the left and right hemidiaphragms, signal amplitude was similar at all measurement time points, indicating similar supramaximal stimulation intensity (fig. 3).

Ten minutes after the end of exercise, the VHV-SB difference in $\mathrm{tw}, P$ mo was $2.0 \mathrm{cmH}_{2} \mathrm{O}$. In contrast, this difference was nonexistent at rest, and nonsignificant ( $p=0.09$ ) $30 \mathrm{~min}$ after the end of exercise (fig. 4).

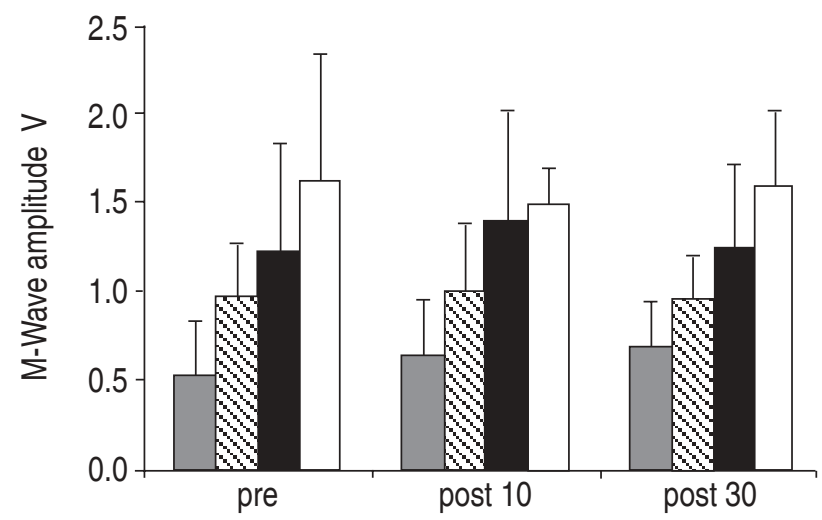

Fig. 3. - Diaphragmatic electromyogram amplitude for the right or left hemidiaphragm before and $10 \mathrm{~min}$ and $30 \mathrm{~min}$ after the end of exercise with spontaneous breathing (SB) or voluntary hypoventilation (VHV). Data are presented as mean \pm SD. 1 : right SB; $\mathbb{\nabla}$ : left $\mathrm{SB} ; \mathbf{\square}$ : right VHV; $\square$ : left VHV. 


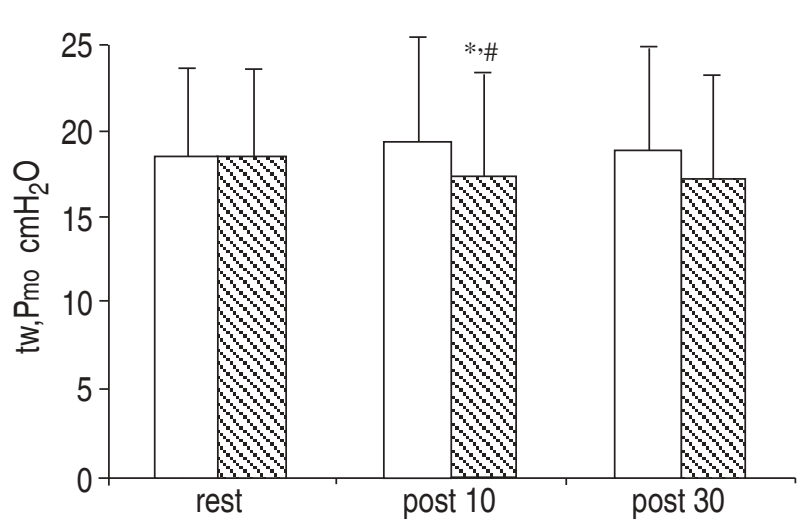

Fig. 4. - Twitch mouth pressure response $\left(\mathrm{tw}, P_{\mathrm{mo}}\right)$ measured at rest, 10 and $30 \mathrm{~min}$ after the end of spontaneous breathing (SB) $(\square)$ or voluntary hypoventilation (VHV) $(\mathbb{\mathbb { Q }})$ exercise test. *: $\mathrm{p}<0.05$ between VHV and SB; ${ }^{\#}: \mathrm{p}<0.05$ compared to baseline.

During VHV, mean tw, $P$ mo decreased significantly from 18.5 before VHV to $17.1 \mathrm{cmH}_{2} \mathrm{O} 10 \mathrm{~min}$ after the end of VHV, while no changes were seen in tw, $P$ mo during SB.

\section{Additional studies}

Study 1: Mean cycling time was $16 \mathrm{~min}$. The subjects reached $88 \% V^{\prime} \mathrm{O}_{2} \max$ during the last 5 min of exercise. Therefore, the conditions previously described [16] to observe exercise-induced diaphragmatic fatigue were fulfilled. At rest, oesophageal and mouth pressures were $21.5 \pm 3.5$ and $21.8 \pm 3.1 \mathrm{cmH}_{2} \mathrm{O}$, respectively and fell to $18.7 \pm 2.6$ and $19.5 \pm 2.5 \mathrm{cmH}_{2} \mathrm{O}$ $10 \mathrm{~min}$ after the end of exercise. The decrease of $17.0 \%$ in $\mathrm{tw}, P$ di (from $30.4 \pm 5.4$ to $25.2 \pm 3.4 \mathrm{cmH}_{2} \mathrm{O}$ ) was due partially to a fall in twitch oesophageal pressure. Mouth pressure reflecting the osophageal component of the pressure generated by the respiratory muscles contraction, the decrease in tw, $P$ mo was only $2.3 \mathrm{cmH}_{2} \mathrm{O}(10.5 \%)$. Averaged individual measurements are shown in figure 5.

Study 2: mean ventilation was 73.2 and $51.5 \mathrm{~L} \cdot \mathrm{min}^{-1}$ during the cycling test performed at 180 and $135 \mathrm{~W}$, respectively. Ten min after the end of the lower exercise, tw, $P$ mo was $19.9 \pm 5.0 \mathrm{cmH}_{2} \mathrm{O}$ compared to $19.7 \pm 4.3 \mathrm{cmH}_{2} \mathrm{O}$ at baseline. For the exercise reproducing the ventilation reached during $\mathrm{SB}$, tw, $P$ mo was $17.0 \pm 3.5 \mathrm{cmH}_{2} \mathrm{O}$ at baseline and $17.6 \pm 5.1 \mathrm{cmH}_{2} \mathrm{O} 10 \mathrm{~min}$ after the end of exercise. The individual variations in $\mathrm{tw}, P$ mo from baseline to $10 \mathrm{~min}$ after one or the other exercise were narrow. No common trend could be identified because these variations were not constant in direction, and were probably due to variability of the measurement than to potentiation itself.

\section{Discussion}

The main findings of this study were as follows: 1) most subjects (12 of 14) were able to decrease their ventilation voluntarily, on average from 68 to $54 \mathrm{~L} \cdot \mathrm{min}^{-1}$, thereby producing pronounced hypercapnia $\left(51 \mathrm{mmHg}\right.$ instead of $\left.41 \mathrm{mmHg} P \mathrm{a}, \mathrm{CO}_{2}\right)$ and
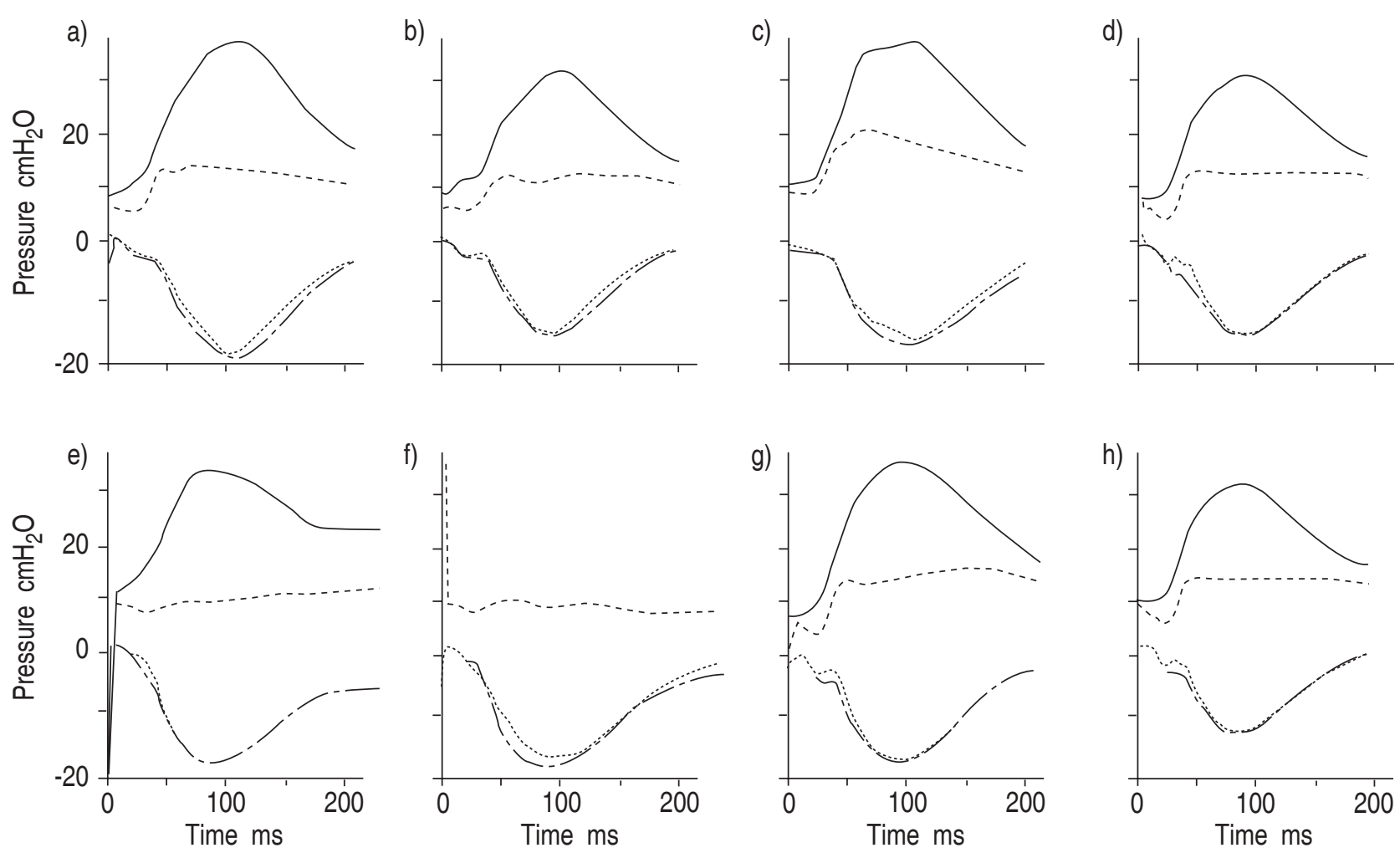

Fig. 5.-Individual mean transdiaphragmatic $\left(P_{\mathrm{di}}\right)$, gastric $\left(P_{\mathrm{ga}}\right)$, oesophageal $\left(P_{\mathrm{oes}}\right)$ and mouth $\left(P_{\mathrm{mo}}\right)$ pressures recorded a), c), e), g) before and b), d), f), h) 10 min after the end of exercise in four subjects. $-: P$ di; $---: P_{\text {ga }} ;-\cdot-: P$ oes; $\cdots \cdots \cdots \cdots: P$ mo. 
acidosis; 2) Ten minutes after the end of exercise, an effect of acidosis on diaphragmatic strength was observed, assessed by a significant decrease of tw, $P$ mo.

\section{Ventilatory work}

While the respiratory load the subjects had to sustain was different during both exercise sessions, the mechanical ventilatory work was carefully standardized, thus ensuring that the effects of acidosis were isolated from those of other factors contributing to diaphragmatic fatigue. Duty cycle and breathing frequency were similar during the VHV and SB tests. The inspiratory-time over total-time ratio was kept constant during all tests. VHV was achieved primarily by a reduction in $V \mathrm{~T}$. It is likely that this reduction in $V \mathrm{~T}$ lightened the work of the respiratory muscles but the pressure-time product was not quantified. However, as the SB exercise was performed at the same intensity as VHV but with a lower $F \mathrm{I}, \mathrm{O}_{2}$ and larger $V \mathrm{~T}$, it can be concluded that it was as demanding or even more demanding for the respiratory muscles as VHV. Furthermore, to maintain constant breathing-motor coordination, the pedalling rate was the same during all tests.

\section{Hypercapnia, $\mathrm{pH}$}

As expected, based on the pronounced $(\mathrm{p}<0.05)$ hypercapnia observed during $\mathrm{VHV}, \mathrm{pH}$ fell during the VHV tests (table 2), thus showing that VHV can effectively induce acidosis without a basic change in mechanical work of ventilation.

\section{Methodological considerations}

The main factors that affect tw, $P$ mo are magnitude of stimulation, quality of electrical input transmission, initial length of diaphragmatic fibres, and ability to generate a force in response to a stimulus. To minimize variations in the magnitude of stimulation, great care was taken to ensure optimal positioning of the coil on the neck. SimiLowski et al. [15] suggested that the EMG should be used to determine whether CMS is supramaximal. Consequently, the site was marked and the power output of the stimulator where the tw, $P$ mo and $M$-wave responses were maximal was noted, and then this site and this power was used for subsequent stimulations. Careful attention was given to standardization of the posture of the subjects. Since there is general agreement that transmission fatigue does not occur during exercise in normal humans [16] and given the constancy of the EMG data during each test, it can be assumed that CMS was maximal and constant.

Evaluation of diaphragm strength by measurement of tw, Pmo previously provided conflicting results [17-20]. In aggregate, it is suggested that a decrease in tw, Pmo indicates inspiratory muscle fatigue. Discrepancies were based on diaphragmatic fibre length (in association with lung volume) at the moment of magnetic stimulation and possible glottis closure, which governs pressure transmission to the mouth. HAMnEGÅR et al. [18] argued that tw, $P$ mo is useful, based on correlation and limits of agreement between mouth and oesophageal pressures. LAGHI and ToBIN [19] reported that the correlation between $t w, P$ mo and tw, $P$ di were relatively weak $(r=0.61, p<0.001)$ in subjects relaxing at FRC. However, two of their subjects showed a close relationship between tw, $P$ mo and tw, $P$ di under the same conditions of stimulation $(r=0.87)$. The results of the first additional study here, supports the use of tw, $P$ mo as an index of fatigue. It was observed that fatiguing exercise caused a decrease in tw, $P$ mo ranging from $2.0-2.5 \mathrm{cmH}_{2} \mathrm{O}$ and a concomitant decrease in tw, $P$ di of $5.2 \mathrm{cmH}_{2} \mathrm{O}$. The methodological conditions were as follows: 1) all stimulations were performed at the same lung volume (i.e. passive FRC) and 2) a small leak was included at the mouthpiece to avoid glottis closure. So it is highly likely that the changes in tw, $P$ mo seen in this study reflect changes in the ability to generate force in response to the stimulus. It is also acknowledged that the magnitude of the fall in tw, $P$ mo is unlikely to exceed $2 \mathrm{cmH}_{2} \mathrm{O}$ within the type of exercise model used in this study. It is further acknowledged that functional consequences of a fall in tw, $P$ mo of this magnitude $(\sim 10 \%)$ remain uncertain.

Changes in the tw, $P$ mo response to electrical stimulation (ES) of the phrenic nerves reflect changes in diaphragmatic contraction alone. This is not the case with CMS [21]. The magnetic field stimulates not only the phrenic nerves (not their roots [22]), but also the brachial plexus and the intercostal nerves, whose activation has non-negligible effects on oesophageal pressure. LAGHI et al. [23] reported that contraction of the accessory inspiratory muscles may account for the larger transdiaphragmatic pressure change following CMS as compared to ES, but found that the transdiaphragmatic pressure variation in response to CMS was nevertheless as accurate as ES for detecting diaphragmatic fatigue. A limitation of this study is the absence of gastric and oesophageal pressure measurements. These pressures are difficult to obtain under the exercise conditions used in the study. Consequently, it can not be confirmed that any tw, $P$ mo change was only due to diaphragmatic fatigue, i.e. would have been uninfluenced by fatigue of accessory inspiratory muscles.

MADOR et al. [24] demonstrated that potentiation takes place after maximal and submaximal voluntary contractions of the diaphragm. This phenomenon fades during recovery, but may mask fatigue for some minutes. Whatever the amplitude of the voluntary contractions, tw, $P$ di had recovered to control value in $8 \mathrm{~min}$. This recovery occurred in $2 \mathrm{~min}$ for the lowest level of contraction. WRAGG et al. [25] demonstrated that for sustained diaphragm contractions the intensity is the major determinant of the degree of potentiation rather than duration. They considered that $20 \mathrm{~min}$ of rest before any measurement guarantees the absence of potentiation. Given the timing of the measurement and the amplitude of expiratory flow in SB as well as in VHV, tw, Pmo must have been only minimally affected by potentiation. Nevertheless, the 
authors agree that $10 \mathrm{~min}$ after exercise, both potentiation and fatigue process were still likely to coexist.

\section{Effect of exercise and of acidosis on twitch mouth pressure response}

The level of exercise used in this study was well under $85 \% V^{\prime} \mathrm{O}_{2} \max$, which is considered as a threshold that can induce diaphragmatic fatigue [26, 27]. Accordingly, the level of exercise used in this study had no effect on tw, $P$ mo when the subjects breathed normally. From the results of the additional studies and from the few rare data about exercise and potentiation, it is hardly arguable that these measurements are affected differently by potentiation. Hence, the $2.0 \mathrm{cmH}_{2} \mathrm{O}$ difference in tw, $P$ mo between VHV and SB observed 10 min after exercise represents the effect of acidosis. It is congruous with the $\geqslant 20 \%$ decrease in tw, $P$ di reported after exercise that leads to exhaustion [26], and hence gathers all the factors that contribute to muscle fatigue. Moreover, the first additional study shows that the expected variations in tw, $P$ mo should not be wide. The decrease in strength, observed in nonpathological subjects, without and with acidosis strongly suggests that acidosis is of physiological relevance.

To conclude, it was investigated whether exerciseinduced acidosis affects diaphragmatic contractility by measuring the mouth pressure response to cervical magnetic stimulation. Voluntary hypoventilation during exercise induced a significant $\mathrm{pH}$ decrease, thus proving effective as a means of inducing acidosis without significantly changing mechanical ventilatory work. A significant decrease in mean twitch mouth pressure response was seen after exercise with voluntary hypoventilation, while exercise with normal breathing had no effect on twitch mouth pressure response. This result may help to understand how ventilatory failure occurs in patients with chronic obstructive lung disease. Recently, inspiratory pressure support has been shown to prolong exerciseinduced lactataemia in patients with severe chronic obstructive lung disease [28]. This study similarly suggests that exposure to hypercapnia may contribute to impaired respiratory muscle function.

Acknowledgements. The authors would like to thank P. Vorger for his helpful contribution to the set-up of experimental device.

\section{References}

1. Loke J, Mahler DA, Virgulto JA. Respiratory muscle fatigue after arathon running. J Appl Physiol 1982; 52: 821-824.

2. Moxham J, Morris AJR, Spiro SG, Edwards RHT, Green M. Contractile properties and fatigue of the diaphragm in man. Thorax 1981; 36: 164-168.

3. Roussos CS, Macklem PT. Diaphragm fatigue in man. J Appl Physiol 1977; 43: 189-197.

4. Coast JR, Haverkamp HC, Finkbone CM, Anderson $\mathrm{KL}$, George SO, Herb RA. Alterations in pulmonary function following exercise are not caused by the work of breathing alone. Int J Sports Med 1999; 20: $470-475$.

5. Babcock MA, Pegelow DF, McClaran SR, Suman OE, Dempsey JA. Contribution of diaphragmatic power output to exercise-induced diaphragm fatigue. J Appl Physiol 1995; 78: 1710-1719.

6. Juel C. Potassium and sodium shifts during in vitro isometric muscle contraction, and the time course of the ion-gradient recovery. Pflügers Arch. 1986; 406: 458-463.

7. Yanos J, Wood LDH, Davis K, Keamy M. The effect of respiratory and lactic acidosis on diaphragm function. Am Rev Respir Dis 1993; 147: 616619.

8. Fitzgerald RS, Hauer MC, Bierkamper GG, Raff $\mathrm{H}$. Response of in vitro rat diaphragm to changes in acid-base environment. J Appl Physiol 1984; 57: 12021210.

9. Lawler JM, Cline CC, $\mathrm{Hu} \mathrm{Z}$, Coast JR. Effect of oxidative stress and acidosis on diaphragm contractile function. Am J Physiol 1997; 273: R630-R636.

10. Shee CD, Cameron IR. The effect of $\mathrm{pH}$ and hypoxia on function and intracellular $\mathrm{pH}$ of the rat diaphragm. Respir Physiol 1990; 79: 57-68.

11. Juan G, Calverley P, Talamo C, Schnader J, Roussos C. Effect of carbon dioxide on diaphragmatic function in human beings. N Engl J Med 1984; 310: 874 879.

12. Mador MJ, Wendel T, Kufel TJ. Effect of acute hypercapnia on diaphragmatic and limb muscle contractility. Am J Respir Crit Care Med 1997; 155: $1590-1595$.

13. Rafferty GF, Lou Harris M, Polkey MI, Greenough A, Moxham J. Effect of hypercapnia on maximal voluntary ventilation and diaphragm fatigue in normal humans. Am J Respir Crit Care Med 1999; 160: $1567-1571$.

14. Similowski T, Fleury B, Launois S, Cathala HP, Bouche P, Derenne JP. Cervical magnetic stimulation: A new painless method for bilateral phrenic nerve stimulation in conscious humans. J Appl Physiol 1989; 67: 1311-1318.

15. Similowski T, Duguet A, Straus C, Attali V, Boisteanu D, Derenne JP. Assessment of the voluntary activation of the diaphragm using cervical and cortical magnetic stimulation. Eur Respir J 1996; 9: 1224-1231.

16. NHLBI Workshop. Respiratory muscle fatigue. Am Rev Respir Dis 1990; 142: 474 480.

17. Yan S, Gauthier AP, Similowski T, Macklem PT, Bellemare F. Evaluation of human diaphragm contractility using mouth pressure twitches. Am Rev Respir Dis 1992; 145: 1064-1069.

18. Hamnegård C-H, Wragg S, Kyroussis D, et al. Mouth pressure in response to magnetic stimulation of the phrenic nerve. Thorax 1995; 50: 620-624.

19. Laghi F, Tobin MJ. Relationship between transdiaphragmatic and mouth twitch pressures at functional residual capacity. Eur Respir $J$ 1997; 10: 530-536.

20. De Bruin PFC, Watson RA, Khalil N, Pride NB. Use of mouth pressure twitches induced by cervical magnetic stimulation to assess voluntary activation of the diaphragm. Eur Respir J 1998; 12: 672-678.

21. Wragg S, Aquilina R, Moran J, et al. Comparison of cervical magnetic stimulation and bilateral percutaneous electrical stimulation of the phrenic nerves in normal subjects. Eur Respir J 1994; 7: 1788-1792. 
22. Similowski T, Straus C, Attali V, Duguet A, Derenne JP. Cervical magnetic stimulation as a method to discriminate between diaphragm and rib cage muscle fatigue. J Appl Physiol 1998; 84: 1692-700.

23. Laghi F, Harrison MJ, Tobin MJ. Comparison of magnetic and electrical phrenic nerve stimulation in assessment of diaphragmatic contractility. $J$ Appl Physiol 1996; 8: 1731-1742.

24. Mador MJ, Magalang UJ, Kufel TJ. Twitch potentiation following voluntary diaphragmatic contraction. Am J Respir Crit Care Med 1994; 149: 739-743.

25. Wragg S, Hamnegard C, Road J, et al. Potentiation of diaphragmatic twitch after voluntary contraction in normal subjects. Thorax 1994; 49: 1234-1237.

26. Mador MJ, Dahuja M. Mechanisms for diaphragmatic fatigue following high-intensity leg exercise. $\mathrm{Am}$ J Respir Crit Care Med 1996; 154: 1484-1489.

27. Johnson BD, Babcock MA, Suman OE, Dempsey JA. Exercise-induced diaphragmatic fatigue in healthy humans. J Physiol 1993; 460: 385-405.

28. Polkey MI, Hawkins P, Kyroussis D, Ellum SG, Sherwood R, Moxham J. Inspiratory pressure support prolongs exercise-induced lactaemia in severe COPD. Thorax 2000; 55: 547-549. 